\title{
HUMOR NUMA HORA DESSAS? A RELEVÂNCIA DO HUMOR PARA A PROFICIÊNCIA EM LEITURA
}

Claudia Moura da Rocha (UERJ)

Resumo: O texto de humor demanda de seus leitores estratégias e habilidades de leitura requeridas para se ler outros tipos de texto. Por essa razão, acreditamos que ele possa ser empregado no ensino de língua portuguesa, a fim de promover a proficiência em leitura, uma vez que seu leitor deverá empregar seu conhecimento de mundo e avaliar o contexto para preencher as lacunas e informações implícitas de um texto. Neste trabalho, partimos das contribuições da Linguística Textual (KOCH, 2002; KOCH; ELIAS, 2006) e da Semiótica, em especial, a sua aplicação ao texto verbal empreendida por Simões (2019), que a denominou de Teoria da Iconicidade Verbal (TIV). Escolhemos como corpus de análise os textos fictícios publicados pelo site Sensacionalista. Palavras-chave: Humor. Leitura. Semiótica. Linguística Textual.

Resúmen: El texto humorístico exige de sus lectores las estrategias de lectura y las habilidades necesarias para leer otros tipos de texto. Por ello, creemos que se puede utilizar en la enseñanza de la lengua portuguesa, con el fin de promover la competencia lectora, ya que su lector debe usar su conocimiento del mundo y evaluar el contexto para llenar los vacíos e información implícita de un texto. En este trabajo partimos de los aportes de la Lingüística Textual $(\mathrm{KOCH}, 2002 ; \mathrm{KOCH}$; ELIAS, 2006) y la Semiótica, en particular, su aplicación al texto verbal realizada por Simões (2019), quien la denominó Teoría de la Iconicidad Verbal (TIV). Elegimos los textos de ficción publicados por el sitio Sensacionalista como corpus de análisis.

Palabras clave: Humor. Lectura. Semiótica. Lingüística textual.

\section{CONSIDERAÇÕES INICIAIS SOBRE A RELEVÂNCIA DO HUMOR PARA A PROFICIÊNCIA EM LEITURA}

Não é recente o interesse pelo humor e suas relações com a linguagem e com o pensamento humano. Esse interesse 
remonta à Antiguidade Clássica e muitos estudiosos já se ocuparam dele desde então. De Aristóteles a Freud, só para citar dois expoentes de áreas diversas, mas interrelacionadas, como a Filosofia e a Psicologia, podemos apontar muitos estudiosos que se interessaram pelo humor, suas características e potencialidades.

O nosso interesse pelo humor também não é recente e surgiu durante os estudos da especialização em Língua Portuguesa (pós-graduação lato sensu), em 1996, quando nos despertou a curiosidade um programa de humor chamado Sai de Baixo. Nesse programa, o recurso ao humor linguístico (também conhecido como humor verbal) era muito explorado e optamos por estudar como a desconstrução de frases feitas, provérbios, construções cristalizadas pelo tempo e pelo uso provocavam o humor.

Em seguida, durante o mestrado em Língua Portuguesa (2003-2005), nossa atenção se voltou para os programas de humor e como eles poderiam ser aproveitados nas aulas de língua materna. Na dissertação "Aprender só...rindo: aulas de português com alegria", analisamos exemplos retirados de programas de televisão e verificamos de que forma poderiam ser aproveitados didaticamente, uma vez que o mote do riso era algum fenômeno de natureza linguística (morfológico, fonológico, sintático, dentre outros). 
E, no doutorado em Língua Portuguesa (2009-2013), em virtude da preocupação crescente com o aproveitamento pedagógico do humor no ensino de Língua Portuguesa, decidimos pesquisar como ocorria o aproveitamento do texto de humor nos livros didáticos de Língua Portuguesa, o que resultou na tese "O humor verbal e o livro didático de Língua Portuguesa: uma análise do aproveitamento didático do humor". Nossa preocupação era investigar se o texto de humor seria apenas um pretexto para o ensino de gramática. Como esses materiais ainda são o principal recurso pedagógico disponível aos professores brasileiros, era mais que relevante estudá-los.

Essa trajetória não seria possível sem a orientação segura e generosa da professora Darcilia Simões, que sempre esteve aberta a esses estudos, indicando-nos caminhos e alternativas acadêmicas para eles. A ela dedico o meu agradecimento pela orientação acadêmica e pela amizade que dela nasceu.

Dentre as alternativas apontadas por Darcilia Simões, que muito contribuíram para os estudos por nós empreendidos, podemos citar a TIV (Teoria da Iconicidade Verbal) (SIMÕES, 2009). A ela recorremos em várias ocasiões, porque vislumbramos sua eficiência para explicar o que ocorria no 
processo de leitura do texto de humor, o que vem sendo já há algum tempo um dos nossos objetos de estudo, principalmente pela necessidade de melhorias do ensino de leitura em nosso país.

Segundo a TIV, palavras e expressões podem orientar ou desorientar o processo de leitura, funcionando como signos orientadores ou desorientadores. Em alguns textos, essa desorientação não é recomendável, pois a ambiguidade dela advinda pode ser prejudicial ao leitor. Imaginemos uma bula de remédio que leve o leitor a ter dúvidas, em vez de esclarecê-las. Nesse caso, palavras e expressões ambíguas (signos desorientadores) são altamente prejudiciais. Entretanto, num poema ou numa piada, a ambiguidade é bem-vinda porque permite a polissemia, o duplo sentido. A desorientação sígnica é intencional neste caso. Uma boa parcela das piadas se baseia em um gatilho, de natureza linguística, que age como um elemento desorientador, pois guia a duas interpretações diferentes que provocam o riso. Em outras palavras, é a ambiguidade, a polissemia que torna o texto engraçado, uma vez que consegue reunir dois scripts onde deveria haver um só, como propôs Raskin (1985):

Para Raskin, o falante tem uma habilidade intuitiva natural para perceber um texto 
como sendo engraçado ou não, isto é, para distinguir uma piada de um texto dito sério. Para tanto, é necessário que duas propriedades semânticas sejam atendidas: em primeiro lugar, para ser uma piada, o texto deve ser parcialmente ou completamente compatível com dois scripts diferentes e, em segundo lugar, deve haver uma relação de oposição entre esses dois scripts. Portanto, dizemos que os dois scripts com os quais um texto é compatível se sobrepõem completa ou parcialmente nesse texto (sobreposição de scripts). Raskin define script como uma grande porção de informação semântica envolvendo a palavra ou sendo evocada por ela. O script é uma estrutura cognitiva internalizada pelo falante nativo e representa o seu conhecimento sobre uma pequena parte do mundo. [...] $\mathrm{O}$ autor ainda esclarece que o termo script pode ser entendido como sinônimo de esquema ou frame. (ROCHA, 2013, p. 24)

Nosso interesse pelo texto de humor reside na conviç̧ão de que quem lê um texto de humor com proficiência é capaz de ler qualquer outro texto, sendo-Ihe possível reconhecer a polissemia, a ironia, os subentendidos e os implícitos. Por essa razão, nossos estudos também enveredaram pelo campo da Pragmática, a ciência que se ocupa da língua em uso, no contexto. Reconhecer as informações implícitas em um texto requer acessar nosso conhecimento de mundo e considerar o contexto em que esse texto está inserido. 
Acreditamos que a proficiência em leitura (que passa também pela leitura do texto de humor) permitirá aos cidadãos brasileiros ocuparem seu lugar legítimo na sociedade, reconhecendo seus direitos e deveres com mais facilidade.

Escrevemos o presente texto ainda sob os efeitos da pandemia de COVID-19. E esse fato nos faz refletir mais ainda sobre a importância da leitura de textos de humor em um período tão triste e desgastante como o atual. Parafraseando Luís Fernando Veríssimo, autor de um livro de poemas intitulado Poesia numa hora dessas?!, perguntamonos: "Humor numa hora dessas?". Sim, acreditamos que o humor é a saída não só para os problemas do ensino de leitura em Língua Portuguesa como para o enfrentamento de tempos tão difíceis.

Por essa razão, analisaremos textos de humor elaborados sobre a pandemia e problemas dela decorrentes, apontando caminhos de interpretação e seu aproveitamento para a formação de leitores proficientes, com o suporte da TIV (Teoria da Iconicidade Verbal) e da Linguística Textual.

\section{CONCEPÇÕES DE LEITURA}

São mais que conhecidas as lacunas que os estudantes brasileiros apresentam em sua trajetória escolar. Muitos não 
conseguem ler e interpretar adequadamente um texto ou realizar as quatro operações matemáticas básicas. Avaliações nacionais e internacionais de leitura, por meio dos baixos índices alcançados, só confirmam a dificuldade encontrada por nossos alunos e futuros profissionais. Nesse cenário, urge desenvolver estratégias que dotem os estudantes das habilidades e competências necessárias.

No que se refere ao ensino de língua portuguesa (e também de outras disciplinas, uma vez que o acesso ao conhecimento disponibilizado por cada uma delas somente é realizado por meio do próprio idioma materno), é necessário, antes de mais nada, esclarecer que concepções de leitura orientam o seu ensino.

A concepção de leitura está intimamente relacionada à concepção de língua e de texto. Se acreditamos que língua é uma representação do pensamento, um espelho dele, o texto será um produto lógico do pensamento (representação mental) do autor, e leitura, por sua vez, será apenas o simples ato de captação das intenções do autor do texto, de suas ideias transmitidas pelo texto. Se consideramos que língua é um código a ser decodificado, um instrumento de comunicação apenas, o texto é um produto a ser decodificado pelo leitor, e a leitura, portanto, não passará de mera decodificação de 
signos, cabendo ao leitor "o reconhecimento do sentido das palavras e estruturas do texto" (KOCH, 2002, p. 13-20; KOCH; ELIAS, 2006, p. 9-12).

Entretanto, modernamente, a concepção interacional (ou dialógica), entende a língua como um espaço de interação, uma forma de agir sobre o outro e, portanto, o texto não é meramente um produto a ser decodificado tampouco a intenção do autor precisa ser captada, sendo o texto "o próprio lugar da interação e da constituição dos interlocutores", e a leitura será, por conseguinte, "uma atividade interativa altamente complexa de produção de sentidos" $(\mathrm{KOCH}, 2002$, p. 13-20; KOCH; ELIAS, 2006, p. 9-12).

Se o professor concebe a leitura como uma atividade interacional, isso significa que não atribui ao leitor um papel passivo, a quem caberia apenas decodificar o texto ou captar as intenções do autor. Ao leitor cabe uma atitude ativa na atividade de leitura, preenchendo as lacunas existentes com seu conhecimento de mundo, por exemplo:

Diferentemente das concepções anteriores, na concepção interacional (dialógica) da língua, os sujeitos são vistos como atores/ construtores sociais, sujeitos ativos que - dialogicamente - se constroem e são construídos no texto, considerado o próprio lugar da interação e da constituição dos interlocutores. Desse modo, há lugar, no 
texto, para toda uma gama de implícitos, dos mais variados tipos, somente detectáveis quando se tem, como pano de fundo, o contexto sociocognitivo [...] dos participantes da interação. (KOCH; ELIAS, 2006, p. 11)

Isso significa que ler ultrapassa a mera decodificação de signos na superfície textual (apesar de ser uma etapa relevante do processo de leitura), sendo uma atividade interativa de construção dos sentidos (tanto por parte do produtor do texto como de seu leitor).

\section{LEITURA E TEORIA DA ICONICIDADE VERBAL}

A Teoria da Iconicidade Verbal, proposta por Simões, oferece ao professor interessado em melhorar o ensino de leitura (e também de escrita) subsídios teóricos para abordar a leitura (e a produção textual) de uma forma mais produtiva. A TIV é uma aplicação da teoria semiótica de Charles Sanders Peirce ao texto verbal, que não foi por ele contemplado a princípio. É mais que necessário salientar que a análise dos aspectos semióticos de um texto favorece a sua leitura crítica, e por que não dizer plena, que é o que se espera de leitores proficientes.

Recorremos a um trecho de nossa tese de doutoramento para esclarecer o que vem a ser a iconicidade e sua relação com os textos: 
Consideramos o texto (seja ele verbal, seja não verbal; seja oral, seja escrito) um objeto concreto, dotado de materialidade (mesmo que só o estejamos ouvindo), no qual somos capazes de identificar marcas e pistas. Em outras palavras, somos capazes de reconhecer a iconicidade presente nos textos; na modalidade escrita, a materialidade plástica é um efeito visual e é captada pelos olhos; na modalidade oral, essa qualidade é um efeito sonoro, auditivo, e é percebido pelos ouvidos. Por essa razão, podemos aplicar a Teoria da Iconicidade Verbal (SIMÕES, 2009, p. 52-62) aos gêneros textuais.

A iconicidade é a qualidade semiótica fundada na plasticidade - propriedade da matéria de adquirir formas sensíveis por efeito de uma força exterior (SIMÕES, 2009, p. 76). Segundo Simões (2009), podemos identificar quatro tipos de iconicidade em um texto: a diagramática, a lexical, a linguístico-gramatical e a isotópica. O reconhecimento da iconicidade nos textos facilita sobremaneira a leitura, oferecendo ao leitor mais ferramentas na sua tarefa de ler e estabelecer sentido(s) para o texto. (ROCHA, 2013, p. 90)

Vejamos mais detalhadamente dois tipos de iconicidade: a lexical e a isotópica. A primeira relaciona-se à seleção lexical empreendida pelo produtor do texto em virtude de seu projeto de texto, enquanto a segunda, às trilhas temáticas encontradas em um texto. 
Sobre a iconicidade lexical, Simões esclarece que:

Seguindo os passos de Gilbert (1975), podemos afirmar que o léxico é o testemunho da realidade; registra a história de uma civilização, a qual reflete seus anseios e valores, configurando-se, portanto, como portador de expressão e interação social. Desse modo, todo e qualquer ser humano partilha de um saber linguístico e armazena, no seu léxico mental, uma somatória de palavras. O domínio desses registros vocabulares é o elo de sua linguagem com o universo cultural circundante. No nível ou tipo denominado iconicidade lexical, discute-se a seleção dos itens lexicais ativados no texto.

Entendemos que o projeto comunicativo que subjaz a qualquer interação produz uma energia mental capaz de ativar signos que possam representar (ícones) ideias ou conduzir (índices) o interlocutor à mensagem básica da comunicação. Assim sendo, tão maior será a iconicidade textual quanto mais hábil seja o enunciador na ativação de itens léxicos. Essa habilidade demanda domínio razoável da língua-objeto, assim como largo repertório. (SIMÕES, 2019, p. 100)

Como se percebe, o eixo da iconicidade lexical é o léxico. Ao ler um texto, o leitor acionará seu conhecimento lexical para identificar as marcas, as pistas fornecidas pelo texto que o auxiliarão na sua busca pelo sentido. Por sua vez, o produtor de textos também acionará seu repertório lexical a 
fim de deixar marcas e pistas para orientar o possível leitor de seus textos.

Em relação ao segundo tipo de iconicidade, a isotópica, Simões (2019, p. 111) esclarece que ela é decorrente das iconicidades diagramática e lexical, funcionando como trilha temática para a formação do sentido.

Segundo a estudiosa,

No plano da análise de textos em geral, a iconicidade isotópica se faz no rastreamento de palavras e expressões que possam sustentar esse ou aquele tema. A garantia dos recortes isotópicos propostos para esse ou aquele texto se assenta exatamente na possibilidade de identificação de itens léxicos (palavras ou expressões) que constituam campos lexicais ou semânticos que ratifiquem a opção temática proposta. (SIMÕES, 2019, p. 112)

É possível deduzir que a presença da iconicidade lexical, por exemplo, auxilia na existência da iconicidade isotópica, o que também pode ser relacionado à estratégia de se empregarem palavras do mesmo campo lexical como um recurso coesivo, conhecido como procedimento de manutenção temática, garantindo a coerência textual $(\mathrm{KOCH}$; ELIAS, 2006, p. 159-160).

Simões se refere a essas pistas ou marcas, identificadas na superfície textual, como âncoras textuais: 
Entendemos por âncoras textuais palavras e expressões ativadas nos textos, as quais atuam como elementos que garantem uma estruturação temática e auxiliam a progressão das ideias no texto. Por meio das âncoras textuais é possível identificar, com maior precisão, as isotopias do texto. A discussão das âncoras textuais poderá ser realizada por meio do levantamento de semas, pela semântica componencial proposta por Pottier (1978), por exemplo. É da identificação das âncoras textuais que se pode inferir a alta ou baixa iconicidade textual. (SIMÕES, 2019, p. 117)

Essas âncoras textuais funcionam como pistas que orientam o leitor em seu percurso pela superfície textual, ao longo do processo de interpretação do texto. Dessa forma, um texto pode apresentar ou alta ou baixa iconicidade:

A iconicidade, no processo da leitura e da redação, a nosso ver, pode manifestar-se de dupla forma: a) como alta iconicidade - qualidade por meio da qual o texto orienta o leitor à produção de sentido em função da apresentação estratégica de pistas de leitura; b) como baixa iconicidade - qualidade por meio da qual o texto se torna opaco, porque não oferece pistas suficientes ou eficientes para o desenrolar da leitura. Convém esclarecer que a alta iconicidade tanto se presta à construção da eficácia quanto à falácia textual. Nesta o leitor é driblado pelas pistas do texto; naquela, é conduzido por elas. (cf. SIMÕES \& DUTRA, 2004: 41) 
Trata-se, portanto, de uma classificação do texto segundo seu potencial icônico, entendendo este como sendo resultante de um conjunto de recursos usados pelo enunciador, destinados a gerenciar a ação do intérprete. Se o texto consegue atingir seus objetivos comunicativos (que podem instruir o leitor ou enganá-lo), classificamo-lo como de alta iconicidade; caso contrário será um texto de baixa iconicidade. (cf. SIMÕES, 2007, p. 43-4). (SIMÕES, 2019, p. 119)

\section{RELEVÂNCIA DO TEXTO DE HUMOR NO ENSINO DE LEITURA}

Sobre a importância do humor, Ziraldo certa vez afirmou:

O humor, numa concepção mais exigente, não é apenas a arte de fazer rir. Isso é comicidade, ou qualquer outro nome que se escolha. Na verdade, humor é uma análise crítica do homem e da vida. Uma análise desmistificadora, reveladora, cáustica. Humor é uma forma de tirar a roupa da mentira, e o seu êxito está na alegria que ele provoca pela descoberta inesperada da verdade. (ZIRALDO apud ARANHA; MARTINS, 1992, p. 53)

Sua fala, por si só, já comprova a relevância de se lerem textos de humor para a formação de cidadãos mais críticos e para revelar a verdade. Ritter afirma que "o riso está diretamente ligado aos caminhos seguidos pelo homem para encontrar e explicar o mundo: ele tem a faculdade de nos fazer reconhecer, ver e apreender a realidade que a 
razão séria não atinge" (ALBERTI, 1999, p. 12). Para Bataille, o riso "permite pensar (experiência refletida) o que não pode ser pensado" (ALBERTI, 1999, p. 15), ou seja, por meio do humor é possível tratar de temas que de forma séria talvez não seja possível ou permitido abordar, é possível alcançar o "impensável”.

Não devemos esquecer que alguns teóricos do humor, como Bergson (2001), identificaram a função corretiva do riso, que serviria para castigar o mau comportamento de elementos da sociedade. No entanto, o humor e o riso não se limitam a essas duas funções. A relevância da leitura de textos de humor na formação de leitores proficientes pode ser defendida pelo fato de que a leitura desses textos requer habilidades e competências que também são requeridas na leitura de textos literários, publicitários, levando o aluno a distinguir, entre os textos que lê, aqueles que devem ser lidos de uma maneira ou de outra.

Para ler textos de humor, e atribuir-lhes sentido, o que muitas vezes resulta no riso (só rimos de uma piada se a entendemos), é necessário, via de regra, identificar o duplo sentido (em algumas teorias do riso, seria equivalente a identificar os dois scripts) decorrente da polissemia ou da homonímia (às vezes da paronímia), que são fenômenos 
da área semântica. Em outras situações, é necessário identificar as informações implícitas ou subentendidas. Habilidades requeridas, como se pode imaginar para ler textos não humorísticos, mas polissêmicos, como os poemas, e até mesmo sérios (mas que apresentam lacunas, uma característica de todos os textos, uma vez que nenhum texto poderia apresentar em sua superfície textual todas as informações a ele relacionadas).

Se o leitor é capaz de reconhecer um texto como humorístico, é, por conseguinte, capaz de identificar que ele não pode ser lido da mesma maneira que se lê um texto não humorístico, um texto dito sério. Raskin (1985, p. 100 101; 104; 131) lembra que, de acordo com o Princípio da Cooperação, proposto por Grice, o falante se compromete com a verdade e a relevância do texto. Esse princípio rege o modo de comunicação bona-fide (modo de comunicação sério, confiável), que é acionado ao lermos determinados textos, como por exemplo, os informativos. A ambiguidade, por exemplo, não é adequada nesse modo. No entanto, ao ler uma piada, por exemplo, o leitor deve acionar o modo de comunicação non-bona-fide, próprio do ato de mentir, de atuar ou de contar uma piada. Nele, a ambiguidade é permitida. Essa habilidade de leitura (reconhecer se um texto 
deve ser lido pelo modo de comunicação bona-fide ou não) pode e deve ser aplicada a outros textos, o que o capacitará, por exemplo, a reconhecer em meio a tantas informações disponíveis, tantas notícias, quais são verdadeiras, quais são falsas (as chamadas fake news).

A análise pelo viés semiótico, procurando identificar a estratégia sígnica proposta pelo autor, vem a auxiliar o leitor no reconhecimento desse tipo de texto:

No momento, ganha destaque uma nova categoria de mensagem: as fake news, ou notícias falsas. [...]

Dessa novidade resulta o aumento da responsabilidade do intérprete quando diante de uma nova informação. Até que ponto será uma notícia confiável? Como traçar limites entre essas fake news, a paródia e a sátira? Essas são algumas das indagações que vêm hoje ocupar a mente dos intérpretes. Portanto, cada vez mais se impõe o conhecimento das estratégias dos signos, para que se possa depreender-lhes um conteúdo dotado de veracidade e do qual não emerjam consequências políticas e ideológicas comprometedoras.

É mister, então, trazer ao texto noções relativas ao domínio da Linguística, para se ir construindo uma amarração indispensável entre Filosofia da Linguagem, Linguística e Semiótica, como componentes de uma compreensão mais segura das coisas do mundo. (SIMÕES, 2019, p. 25-26) 
Recorremos a Simões para ressaltar o que anteriormente defendemos, uma leitura crítica, que leve o leitor a duvidar do que lê, que o leve a identificar a estratégia sígnica do autor do texto, a fim de refletir sobre os textos que encontra em seu cotidiano:

Com essas palavras, Morin nos ajuda a compreender a necessidade de observaremse os signos, em especial os verbais que são foco da proposta teórica deste volume - com olhos de desconfiança. A compreensão do tecido verbal carece de profunda capacidade de duvidar, para que o produto final - a interpretação - esteja o mais próxima possível da verdade do texto. Mesmo sabendo-se da relatividade da verdade, pode-se falar de verdade textual, uma vez que cada texto constitui um mundo particular que precisa ser desvendado pelo intérprete (leitor). Se estamos sob um paradigma de complexidade, mais se exige da compreensão e da interpretação de tecidos textuais que emergem desse modelo de raciocínio. (SIMÕES, 2019, p. 56-57)

\section{ANÁLISE DO CORPUS: HUMOR E PANDEMIA}

A seguir, realizamos a análise de três textos publicados pelo site de humor Sensacionalista, que publica notícias fictícias. O leitor do site precisará ler essas notícias selecionando o modo de comunicação non-bona-fide, pois não são notícias verdadeiras nem devem ser encaradas como tais. A esse leitor, 
portanto, não cabe apenas decodificar o código em que o texto está escrito, muito menos apenas captar a intenção do autor. Como vimos, em uma concepção interacional de leitura, que é a que propomos nesta análise, o leitor apresenta uma postura ativa, pois a ele caberá recorrer a seus conhecimentos de mundo e preencher as lacunas textuais, realizando inferências e identificando as informações implícitas.

Leiamos os dois textos:

Brasil morreu na praia, dizem especialistas

Foram meses e meses de tentativas de isolamento social para conter a pandemia de covid-19, mas bastou um fim de semana de sol para tudo ir por água abaixo. Em diversos pontos do litoral brasileiro foram registradas aglomerações nas praias.

"Foram meses nadando para morrer na praia", é o que dizem especialistas sobre o Brasil no combate à pandemia. Mas segundo historiadores, o Brasil já havia morrido na praia bem antes em abril de $1500 .^{1}$

Homem que ainda estava de quarentena é declarado morto pela família e amigos

O último brasileiro que ainda respeitava as regras de isolamento social completo para evitar a contaminação pelo coronavírus foi declarado morto na tarde de ontem.

1 Disponível em: https://www.sensacionalista.com.br/2020/08/31/brasil-morreu-na-praiadizem-especialistas/. Acesso em 14/01/2021. 
Gilmar Fernandes, no entanto, não contraiu nenhuma doença nem teve um mal súbito. Ele simplesmente foi esquecido por todos porque não sai de casa além do necessário - e hoje, com aplicativos de entrega de compras, o necessário para ele é nunca.

"Já fui a cinco batizados, três festas de 15 anos, 18 casamentos, oito enterros e não vi mais o Gilmar. Eu e uns amigos fomos na delegacia e descobrimos que pudemos declarar que ele estava morto. Agora vai todo mundo se reunir de novo para o enterro", disse o amigo Leonardo Fagundes. ${ }^{2}$

A leitura destes dois textos permite entrever uma crítica àqueles que não respeitam o isolamento social. No primeiro, há referência às praias lotadas nos fins de semana; no segundo, às pessoas que já desistiram do isolamento social e ao fato de que quem o respeita é visto como diferente, podendo até ser esquecido.

Analisando os dois textos, poderemos reconhecer uma seleção lexical de palavras e expressões relacionadas a um determinado campo lexical que colaboram para a manutenção temática, ou seja, um procedimento coesivo que garante a coerência textual (KOCH; ELIAS, 2006, p. 159160). Além desse tipo de análise, podemos realizar uma pelo viés semiótico, empregando a TIV para referendá-la.

2 Disponível em: https://www.sensacionalista.com.br/2020/10/21/homem-que-aindaestava-de-quarentena-e-declarado-morto-pela-familia-e-amigos/. Acesso em 14/01/2021. 
Em relação ao primeiro texto, "Brasil morreu na praia, dizem especialistas", podemos apontar a presença de palavras e expressões relacionadas ao campo lexical da praia (e, consequentemente, da água): morreu na praia, fim de semana de sol, ir por água abaixo, litoral brasileiro, praias, nadando para morrer na praia, havia morrido na praia. Duas expressões merecem nossa atenção por se tratarem de expressões metafóricas, de natureza conotativa, ou seja, não podem ser interpretadas literalmente: morrer na praia e ir por água abaixo. Essas duas expressões são ambíguas e funcionam como signos desorientadores, uma vez que remetem a duas interpretações. Em uma notícia de jornal verdadeira, isso seria um problema, mas como se trata de humor, e sua escolha foi intencional, deliberada, não é interpretada como um equívoco, pois neste tipo de texto, na maioria das vezes, uma palavra polissêmica, que gera a ambiguidade, atua como o gatilho que desencadeia o riso. Ao fazer esse levantamento (ou melhor dizendo, rastreamento) das palavras e expressões, estamos nos referindo à iconicidade lexical. Morrer na praia e ir por água abaixo se referem ao fato de que os objetivos, apesar de todos os esforços, não foram atendidos. Essas unidades do léxico, intencionalmente escolhidas pelo autor do texto, reforçam o tema do texto, 
ou seja, reforçam as trilhas temáticas existentes. Aqui nos referimos à iconicidade isotópica.

Percebe-se, por meio da seleção lexical (de palavras e expressões), que essa não foi aleatória, mas intencional. O objetivo é fazer uma crítica (lembremos da função corretiva do riso) não só àqueles que não seguem as regras do isolamento, como também aos políticos (neste caso, mencionando os "descobridores" do Brasil, o que se infere pela menção à data "abril de 1500". Como um dos locais escolhidos pela população tem sido a praia, nos fins de semana, nada melhor que realizar uma seleção lexical que contemple a praia e assuntos correlatos. O leitor não deve ler esse texto literalmente, mas acionar o modo de leitura non-bona-fide, que nos indica que o texto é de humor. Essa habilidade permitirá ao leitor identificar outros tipos de texto que não podem ser lidos pelo modo de comunicação bona-fide, o modo confiável, como as fake news. Ou seja, não devemos confiar em notícias falsas.

Por sua vez, no segundo texto, "Homem que ainda estava de quarentena é declarado morto pela família e amigos", também é possível identificarmos uma seleção lexical que reforça as trilhas temáticas existentes. Palavras e expressões como quarentena, regras de isolamento social completo, 
contaminação pelo coronavírus, morto, doença, mal súbito, não sai de casa, aplicativos de entrega de compras remetem ao campo lexical da pandemia, enquanto batizados, festas de 15 anos, casamentos e enterros remetem ao campo lexical das celebrações e ritos de passagem da nossa sociedade. A palavra enterro tanto pode pertencer ao primeiro quanto ao segundo campo lexical. Notamos, por meio da iconicidade lexical, a existência de duas trilhas temáticas, a iconicidade isotópica: a da doença e a das ocasiões e festividades em que as pessoas não cumprem 0 isolamento social recomendado pelas autoridades de saúde. O texto provoca o riso pelo insólito da situação: alguém ser declarado morto não por ter morrido em virtude do coronavírus, mas por ter sido esquecido, uma vez que respeitava o isolamento social. Novamente, identificamos uma crítica ao comportamento de parte da sociedade que se recusa a respeitar o distanciamento social.

No terceiro texto, "Brasileirão: clubes negociam direito de transmissão do coronavírus nos estádios", apresentado a seguir, o "gatilho" para desencadear o riso é a expressão "direito de transmissão", muito usual no mundo dos esportes (os clubes de futebol costumam negociar com as emissoras de televisão os direitos de transmissão das partidas de que participam em troca de vultosas quantias). 
Brasileirão: clubes negociam direito de transmissão do coronavírus nos estádios

Os clubes estão em negociação sobre o direito de transmissão do coronavírus nos estádios de futebol. A disputa começou com a MP do presidente Jair Bolsonaro que deu ao mandante do campo a liberdade para negociar com emissoras.

Com a chegada do brasileiro [(sic)], os clubes se animaram. Essa não será a única novidade: o brasileirão desse ano pode incorporar a morte súbita. ${ }^{3}$

Neste caso, a palavra transmissão é polissêmica, gerando ambiguidade que, nesse texto, não é prejudicial ao seu entendimento, ao contrário é intencional, pois remete tanto ao "envio de informação sonora ou visual por meio de ondas eletromagnéticas" quanto ao "ato, processo ou efeito de transmitir(-se)" (HOUAISS: VILLAR, 2009, p. 2752), nesse caso, o coronavírus. Essa expressão pode ser considerada um signo desorientador porque produz ambiguidade, porém essa ambiguidade é estratégica, intencional, fazendo parte do projeto de texto do autor. Identificam-se palavras e expressões relacionadas ao campo lexical do futebol, como Brasileirão (nome de um famoso campeonato), clubes, negociam, direito de transmissão, estádios, negociação,

3 Disponível em: https://www.sensacionalista.com.br/2020/07/15/brasileirao-clubesnegociam-direito-de-transmissao-do-coronavirus-nos-estadios/. Acesso em 14 jan. 2021. 
estádios de futebol, disputa, mandante do campo, negociar, brasileiro (sic). Outro campo lexical presente no texto é o das emissoras de televisão, identificado por meio de palavras e expressões, como direito de transmissão e emissoras. O texto faz referência à morte súbita, expressão que tanto pode se referir ao universo dos esportes quanto ao da saúde, uma vez que significa, respectivamente, um critério de desempate do futebol, em que, havendo prorrogação, vence a equipe que marcar o primeiro gol, e à morte "[...] que é inesperada, inopinada, sobrevindo a um indivíduo que aparentemente goza de boa saúde" (HOUAISS; VILLAR, 2001, p. 1964). Essa expressão, juntamente com direito de transmissão, é um dos gatilhos desencadeadores do riso, porque remete a dois scripts, o dos esportes e o da doença. É possível ao leitor inferir essa informação, porque a transmissão da doença ocorreria em campo, com os jogadores defendendo seus times, o que poderia levar à contaminação pelo vírus e a uma possível morte.

Nesse texto também foi possível identificar a iconicidade lexical por meio do levantamento de palavras e expressões relacionadas a determinados campos do léxico. Essas palavras auxiliam na construção das trilhas temáticas (a iconicidade isotópica), garantindo a coerência textual. 
Os três textos apresentam alta iconicidade, uma vez que seus autores alcançam seus objetivos comunicativos, sendo-nos possível identificar, por meio do levantamento de palavras e expressões pertencentes ao mesmo campo lexical (a iconicidade lexical), as trilhas temáticas existentes (a iconicidade isotópica).

\section{CONSIDERAÇÕES FINAIS}

É notório o fraco desempenho de nossos estudantes quando se trata de leitura e interpretação textual. Por essa razão, é urgente buscar soluções que viabilizem a aquisição de habilidades e competências de leitura por parte de nossos alunos. Propomos a leitura de textos de humor como uma estratégia para o desenvolvimento dessas habilidades. Ler um texto de humor requer estratégias e habilidades de leitura que são exigidas para ler outros tipos de texto, o que o torna uma excelente ferramenta para o desenvolvimento da proficiência em leitura.

Para levar adiante esta proposta, é necessário que o professor se conscientize de que a leitura não é uma atividade passiva, ao contrário, espera-se que o aluno seja figura ativa nesse processo. Essa é a premissa de uma concepção de leitura que seja interacional, como a proposta pela Linguística Textual (KOCH, 2002; KOCH; ELIAS, 2006). 
De acordo essa concepção, ao aluno não cabe apenas decodificar os signos encontrados na superfície textual, muito menos captar a intenção do autor. Ao leitor cabe recorrer ao seu conhecimento de mundo, inserindo o texto lido no seu contexto, a fim de preencher as lacunas do texto, recuperando também os seus implícitos.

Propomos uma análise de textos de humor calcada na TIV (Teoria da Iconicidade Verbal), que vem a ser a aplicação da teoria semiótica de Peirce ao texto verbal, empreendida por Simões (2019). A estudiosa nos aponta alguns tipos de iconicidade que podem ser encontradas nos textos, dentre as quais a lexical e a isotópica, que elegemos como parâmetros para analisar o corpus. A primeira se refere à seleção lexical, à escolha estratégica das palavras de um texto, de acordo com o projeto de texto que se pretende produzir. A segunda, por sua vez, se refere às trilhas temáticas existentes em um texto. Por meio do levantamento de palavras pertencentes ao mesmo campo lexical, é possível identificar os temas que predominam nos textos, ou seja, verificar se ocorre a manutenção temática, um dos recursos coesivos que pode ser utilizado (KOCH; ELIAS, 2006).

Ao produzir um texto, seu autor elabora um projeto estratégico que visa a alcançar seus objetivos. Se isso 
ocorre, podemos dizer que no texto ocorre a alta iconicidade. Do contrário, podemos dizer que a iconicidade do texto é baixa.

Em se tratando de textos de humor, neles podem ocorrer signos desorientadores, palavras e expressões polissêmicas que geram a ambiguidade. Essa desorientação é estratégica e intencional, fazendo parte do projeto de texto do autor. Normalmente, esses signos desorientadores são os "gatilhos" que desencadeiam o riso.

Os textos analisados, além de apresentarem alta iconicidade (porque seus objetivos comunicativos são alcançados), nos permitem fazer o levantamento de palavras e expressões relacionadas a um campo lexical (iconicidade lexical) e as trilhas temáticas encontradas no texto (iconicidade isotópica). Em dois deles, foi possível identificar signos desorientadores, ambíguos, em decorrência da polissemia de uma palavra ou expressão, que remetem a duas interpretações. No entanto, essa desorientação é estratégica e intencional.

Além de poder contribuir para o ensino de leitura em nosso país, por requerer estratégias e habilidades de leitura, o texto de humor também possibilita pensar o "impensável", pensar sobre coisas que a razão séria não 
permite. O texto de humor nos revela a verdade por um outro viés. Ele nos permite enxergá-la por um novo prisma. No momento atual, em que a grande maioria da população do planeta busca sobreviver a uma pandemia, o humor permite refletir sobre o mundo de maneira mais crítica, apresentando também uma função corretiva.

Notícias sobre o desrespeito às medidas de isolamento se tornam cada vez mais comuns, e o texto de humor do site Sensacionalista, por meio do riso, nos permite refletir sobre o comportamento de uma parcela da população. Como sabemos, o humor também apresenta uma função corretiva, castigando aqueles que descumprem o distanciamento social. Respondendo à pergunta proposta inicialmente, "Humor numa hora dessas?", acreditamos que o texto de humor é a saída não só para os problemas do ensino de leitura em Língua Portuguesa como também para o enfrentamento de tempos tão difíceis.

\section{REFERÊNCIAS}

ALBERTI, Verena. O riso e o risivel: na história do pensamento. Rio de Janeiro: Jorge Zahar Editor/FGV, 1999.

BERGSON, Henri. $O$ riso: ensaio sobre a significação da comicidade. São Paulo: Martins Fontes, 2001.

Brasil morreu na praia, dizem especialistas. Sensacionalista. 31 ago. 2020. Disponível em: https://www.sensacionalista.com.br/2020/08/31/brasilmorreu-na-praia-dizem-especialistas/. Acesso em 14 jan. 2021. 
Brasileirão: clubes negociam direito de transmissão do coronavírus nos estádios. Sensacionalista. 15 jul. 2020. Disponível em: https://www. sensacionalista.com.br/2020/07/15/brasileirao-clubes-negociam-direitode-transmissao-do-coronavirus-nos-estadios/. Acesso em 14 jan. 2021.

Homem que ainda estava de quarentena é declarado morto pela família e amigos. Sensacionalista. 21 out. 2020. Disponível em: https://www. sensacionalista.com.br/2020/10/21/homem-que-ainda-estava-dequarentena-e-declarado-morto-pela-familia-e-amigos/. Acesso em 14 jan. 2021.

HOUAISS, Antonio; VILLAR, Mauro de S. Dicionário Houaiss de língua portuguesa. Rio de Janeiro: Objetiva, 2001.

$\mathrm{KOCH}$, Ingedore Villaça. Desvendando os segredos do texto. São Paulo: Cortez, 2002.

$\mathrm{KOCH}$, Ingedore Villaça; ELIAS, Vanda Maria. Ler e compreender: os sentidos do texto. São Paulo: Contexto, 2006.

RASKIN, Victor. Semantic mechanisms of humor. Dordrecht: D. Reidel Publishing Company, 1985.

ROCHA, Claudia Moura da. O humor verbal e o livro didático de Língua Portuguesa: uma análise do aproveitamento didático do humor. Orientadora: Darcilia Simões. 2013. 381f. Tese (Doutorado em Língua Portuguesa) - Instituto de Letras, Universidade do Estado do Rio de Janeiro, Rio de Janeiro. 2013.

SIMÕES, Darcilia. Para uma Teoria da Iconicidade Verbal. Campinas, SP: Pontes Editores, 2019.

Claudia Moura da Rocha é doutora em Língua Portuguesa pela Universidade do Estado do Rio de Janeiro (UERJ), onde leciona como professora adjunta do Departamento de Língua Portuguesa, Literatura Portuguesa e Filologia. Atua na Graduação e na Pósgraduação lato sensu. É professora da rede municipal do Rio de Janeiro, já tendo lecionado no Ensino Fundamental (10 segmento) e Ensino Médio. É membro do grupo SELEPROT.

E-mail: claudiamoura@infolink.com.br. 